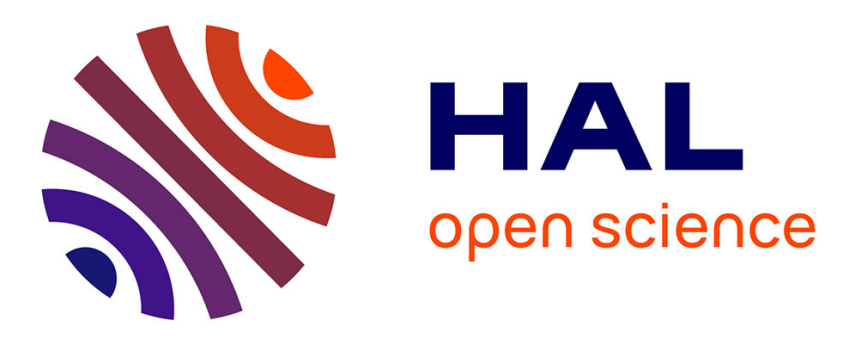

\title{
Aligning EAP writing pedagogies across European universities: a case study from France \\ Dacia Dressen-Hammouda
}

\section{To cite this version:}

Dacia Dressen-Hammouda. Aligning EAP writing pedagogies across European universities: a case study from France. Inmaculada Fortanet-Gómez and Christine A. Räisänen. Toward a Harmonized European Higher Education: English as the Medium of Teaching and Learning, John Benjamins, pp.75-96, 2008, 9789027205209. hal-01011834

\section{HAL Id: hal-01011834 \\ https://hal.uca.fr/hal-01011834}

Submitted on 25 Jun 2014

HAL is a multi-disciplinary open access archive for the deposit and dissemination of scientific research documents, whether they are published or not. The documents may come from teaching and research institutions in France or abroad, or from public or private research centers.
L'archive ouverte pluridisciplinaire HAL, est destinée au dépôt et à la diffusion de documents scientifiques de niveau recherche, publiés ou non, émanant des établissements d'enseignement et de recherche français ou étrangers, des laboratoires publics ou privés. 
In I. Fortanent-Gómez and C. Räisänen (Eds). 2008. Toward a Harmonized European

Higher Education : English as the Medium of Teaching and Learning. Amsterdam: John Benjamins, AILA Applied Linguistics Series, pp. 75-96.

\title{
Aligning EAP writing pedagogies across European universities: a case study from France
}

Dacia Dressen-Hammouda

UFR LACC, Université Blaise Pascal, Clermont 2

\begin{abstract}
The Bologna process has drawn increasing attention to the ways in which English is taught at universities throughout the E.U. One widely used approach to EAP writing instruction combines process-oriented and genre-based pedagogies. The present study explores the crosscultural adaptability of these pedagogies by reporting on the results of a three-year researchaction project, designed to adapt a process-genre approach to teaching EAP writing tasks in a French university setting. The results underscore the cultural embeddedness of the processgenre approach and call into question whether a total alignment of English language writing instruction on process-oriented and genre-based methodologies would be a positive development in the LMD harmonization process.
\end{abstract}

\section{Introduction}

In the literature, English for Academic Purposes is overwhelmingly defined as a process-oriented and genre-based approach to writing instruction, whose features are well established within decades of research in applied linguistics, rhetoric and L1/L2 composition studies. EAP writing instruction often involves increasing students' integral genre awareness (Swales \& Feak 1994, Johns 1997, Hyland 2004), fostering an appreciation of writing genres as an ongoing, rhetorical process (Freedman \& Medway 1994, Hyland 2003), as well as teacher-student or student-student dialogue as a means for developing written discoursal competence (Ferris 1997, Paulus 1999, Tuzi 2004, Goldstein 2004, Hyland \& Hyland 2006). These aspects of EAP have been gaining increasing attention from teachers of academic writing throughout Europe (Bjork et al. 2003).

Approaches to EAP writing instruction thus draw on current understandings of how L1 and L2 students acquire and develop specialized written language skills. Indeed, a processoriented, genre-based approach to EAP writing instruction seeks to simultaneously capture the universality of cognitive writing processes (Bizzell 1992), the regularities of discoursal form (Swales 1990, Bhatia 1993) as well as the dynamics resulting from people having different purposes in different contexts (Halliday 1994, Bhatia 1999, Hyland 2003). For this reason, the approach potentially appears quite useful for teaching EAP writing tasks throughout European universities, especially as it would align teaching approaches in accordance with the 
harmonization project currently underway throughout European institutions of higher education.

That being said, however, it is also clear that the approach relies heavily on the learning and teaching conditions more characteristic of Anglo-Saxon and northern European educational institutions, raising issues of compatibility when used cross-culturally. For example, the approach encourages expectations of student autonomy and dialectical teacherstudent relationships. The cultural schemas underlying these expectations may very well come into conflict when the approach is used in other educational systems of continental Europe, as has recently been suggested by Rienecker and Stray Jörgensen (2003: 101).

The present study will address this issue by reviewing the results of a case study undertaken at a local French university. This chapter describes the results of a three-year research-action project during which a process-genre approach to teaching EAP writing tasks was adapted to fit the needs and expectations of third-year French undergraduate students. Given that France has an institutional and social history of education that is unique to it, it can be hypothesized from the outset that educational expectations among its university students differ from those of their European counterparts. This difference in turn raises the question of whether approaches to EAP writing instruction in European universities can in fact be aligned.

The chapter begins by describing how EAP writing instruction is often processoriented and genre-based. It will then describe the step-by-step adaptation of the approach to a program in language and business at a local French university. In order to better explain the French students' reaction to the approach, the chapter will then briefly examine the educational profile of French student writers. On the basis of this examination, it is questioned whether a process-genre approach to teaching EAP writing tasks can be equally applied to different cultural contexts. Drawing on this observation, the chapter concludes by challenging an often unstated assumption that 'harmonization', whether across teaching methods or university structures, is necessarily a positive development.

\section{A process-oriented and genre-based approach to teaching EAP}

Often, process and genre pedagogies are described being as distinct teaching approaches (Hyland 2003). Although these pedagogies have been thoroughly described in the literature, it is important for the purposes of this chapter to identify the cultural assumptions that underlie them. This, in turn, can provide insight into possibilities for aligning EAP 
teaching methods across European universities. Hyland's (2003) discussion of these concepts provides a good overview of potential areas of cultural incompatibility.

Hyland begins his discussion by citing Zamel's (1983) description of process writing as a "non-linear, exploratory and generative process, whereby writers discover and reformulate their ideas as they attempt to approximate meaning" (1983: 165, cited in Hyland 2003: 18). In this view, writing is seen as a cognitive, problem-solving process where the teacher's primary role is to be "non-directive and facilitative" (Hyland 2003: 18). Rather than transmitting their own preconceived notions of what to say and how to write it, writing instructors who use a process approach assist student writers in expressing their own understanding of the writing task in "an encouraging and co-operative environment with minimal interference" (op. cit.). The EAP writing instructor's primary opportunity for teaching comes at the response stage to writing; at this point, the instructor engages students in a dialogue to encourage them to explore their 'own voice' and to implicate them in their genre mastery. The process approach thus implies that there is a reader on the other end and that, as a dialectical process, writing must be reader rather than writer-oriented.

At the same time, however, process pedagogies also draw heavily on the cultural knowledge typical of many middle-class, largely Anglo-Saxon or northern European institutional practices, which are often not easily accessible to L2 writers from other cultures (Cope \& Kalantzis 1993). For example, process pedagogies promote a model of learning that requires "individual motivation, personal freedom, self-expression and learner responsibility" (Hyland 2003: 19). As Hyland (2003: 20) further observes, the process approach functions on the basis of a culturally situated ideology of individualism, where developing students' personal voice, encouraging critical thinking and using peer review are a central part of the pedagogy. This ideology, however, may very well be unfamiliar to students from other educational systems, such as the French students described in this study.

Hyland (2003: 18-21) identifies a number of other cross-cultural limitations in a process approach to L2 writing pedagogy, but one observation he makes has particular relevance to the current study. This is the observation that "discovery-based" learning, another culture-rich behavior, often fails to provide sufficient scaffolding to L2 student writers (2003: 19). We will return to possible reasons for this observation in later sections, as it is key in understanding the reactions of the French students who participated in the study.

To balance the ideologically grounded view process-oriented writing pedagogies often embody, Hyland argues for using socially-oriented genre pedagogies to teach L2 writing (e.g., Swales 1990, Freedman \& Medway 1994, Halliday 1994, Johns 1997, Hyland 2004). Indeed, 
while the process approach views writing to be so fundamental (i.e., cognitive) as to be universal (Bizzell 1992), the genre approach recognizes that people do not just write, they write to accomplish different purposes in different contexts (Halliday 1994, Bhatia 1999, Hyland 2003). As explained by Hyland (2003: 21), the term 'genre' in writing pedagogy refers to

abstract, socially recognized ways of using language. It is based on the assumptions that the features of a similar group of texts depend on the social context of their creation and use, and that those features can be described in a way that relates a text to others like it and to the choices and constraints acting on text producers.... [A successful text] will display the writer's awareness of its context and the readers who form part of that context.

A socially-oriented, genre-based approach to writing instruction shares process writing's concern for dialogue and a rhetorical understanding of the writer's relationship to readers. At the same time, it also builds on the abstract, socially recognized and momentarily stabilized language patterns that arise from writing's contexts of creation and use. Recognizable patterns across a group of texts are tied to their users' social purposes and contexts. In this regard, genre pedagogies help scaffold students' learning processes by making them more explicitly aware of the genres to be learned and of the ways in which typified language recreates shared social meanings (Hyland 2003: 21). Such scaffolding allows L2 writers to better engage with the "socio-political realities of [their] everyday lives and target situations" (2003: 20).

Whatever the distinctions between process and genre-based pedagogies, the natural overlap between the two can be as useful as it is complementary in designing an EAP course for L2 writers. Clearly, L2 writers need more structural support than is provided by process writing's penchant toward undirected learning. At the same time, in order to be effective learners, L2 writers also need more flexibility and 'process' than simply memorizing discoursal forms, grammatical rules, or word lists. A process-genre writing pedagogy simultaneously teaches the social, rhetorical and structural aspects of writing whereby the learner progresses by dialogically confronting an understanding of a genre's 'rules' with more experienced genre users' own use.

The primary question to be addressed throughout the remainder of this chapter is to what extent a process-genre approach may be successful in helping French L2 student writers gain mastery over the written genres of their disciplines. To answer this question, the results of a three-year action-research project will be described below. 


\section{Adapting a process-genre approach to a French student audience}

The purpose of the following sections will be to describe the results of the project, which adapted a process-genre based approach to teaching EAP written tasks to French university students enrolled in a language and business degree. The step-by-step adaptation of the approach to the students' learning conditions and expectations will be described. Given its focus on one local community, this chapter reports on a case study which, while it cannot pretend to generalize descriptions of social behavior, may raise a number of questions that merit further study.

At the time of the study, the students enrolled in the EAP course described here were all in their final (i.e., third) year of their Bachelor's degree in an Applied Foreign Languages for Business and Technology program ('LEA', or Langues étrangères appliquées). In addition to two foreign languages (English and one other), students in the program further specialize in international trade, business and European law, management, finance, economics and marketing in order to gain a foothold in a rapidly changing professional world. By the time they take the professionally-oriented EAP course during their third year, the students have also completed two or more company work placements; they have thus become familiarized with both the context of the workplace as well as with the specialized tasks and language needed to carry them out. The teaching methods described here must therefore bridge the gap between the process-oriented and genre-based aspects of EAP, by preparing the students for more specific applications in EPP (English for Professional Purposes) at the Masters level.

Because the EAP course described here was the first time the students had experienced a process-oriented and genre-based approach to language learning, careful attention was paid to the way in which they reacted to the course. To understand their reaction, we will first examine the first-day handouts distributed successively over the study's three-year period. While a first-day handout clearly cannot summarize everything an instructor says over the course of a semester, the language used may prove interesting in how it reveals the instructor's underlying assumptions and expectations about the pedagogical exchange.

The students' reactions to the approach were then documented by means of an end-ofthe-semester questionnaire in which their observations about the usefulness and accessibility of the course were solicited. The questionnaires were then used to adapt the teaching methods to better meet new students' needs and expectations the year following. 


\section{First application of the process-genre approach}

The following course description was distributed to students the first time the course was taught:

This course is designed to introduce you to and give you extensive practice of the discoursal, grammatical and lexical structures of written Professional English. The basic premise underlying this approach is that using language is about strategic social communication, rather than just about using words or grammar from a list. Rather, language is always about using 'words for a purpose'. Therefore, you need to know about your communicative situation and use that knowledge to strategically plan what to write. The following factors will influence how you do that:

(1) Audience. One thing we consider during a communicative interaction is the audience and our positioning to it: whom we are addressing, the position of the addressee, the relationship between the writer and the addressee, who else may read the text, what information can be understood easily, what needs further explanation, what attitude we can expect the addressee will have toward the document, what possible objections he/she may have and the reasons for their objection, etc.

(2) Purpose. Effective communication involves more than reproducing correct sentences. If your intended audience is seriously misjudged or ignored, no amount of grammatical editing or terminological finesse will make the communication succeed. Therefore, you must also know what you want to do with your text, or what your purpose is: what you want your readers to do after they read the text, how you want them to react, when you want them to take action and what kind of action you want them to take, if any.

(3) Strategy. You also need to think about how exactly you are going to carry out your purpose using language: what words to use, how to order them, how to put them into sentences, and how to string your sentences together.

(4) Structure. Most writing, even short pieces of writing, have regular, predictable patterns of organization. You can take advantage of these patterns, so that readers can still follow you even if you make errors. Research shows that if you say 'the right things at the right time', grammar mistakes become less of a hindrance to readers' understanding. Therefore, we will also be focusing explicitly on patterns of textual and argumentative organization.

(5) Style. The language choices you make reflect your situation: your audience, your purpose and your strategy. Much of the specialized terminology and grammatical structures that characterize a particular text type respond directly to the text's typical situation. We say that the style has 'normalized'.

The strategies for writing you learn in this class are tools that can be used time and again, outside of and well beyond the walls of this classroom.

\section{"Give a man fish, he will eat for one day. Teach a man to fish and he will eat for a lifetime."}

-Chinese proverb

In the first version of the course, a combination of both process and genre approaches were used to draw students' attention to rhetorical reader-writer dialogue and genre structure. An underlying expectation of progressively moving students toward a greater autonomy in their writing was also present ('Teach a man to fish and he will eat for a lifetime'). 
Various aspects of the process approach were apparent in the instructor's writing pedagogy, such as: (1) recognizing the influence and importance of task on writing outcome; (2) using models of expert writing strategies to guide students' awareness of task; and (3) assuming that discovering one's own path to meaning-making and rule construction was an important cognitive element of individual learning. These process-oriented aspects were closely informed by genre-based pedagogies and L2 research on language acquisition, such as the 'U-curve' of learning, whereby learning is consolidated only once the student has reinvented the language rules for her or himself. For this reason, standard corrections of the target genre were not provided after the assignment was given.

Various aspects of the genre approach were also apparent, such as analyzing expert productions of the target genre, and examining the genre's discourse structure, language and socio-rhetorical context. Students were led to think about how social and rhetorical contexts may affect writing outcomes. The purpose was to equip students with explicit knowledge about various writing contexts, language and strategies in order provide them with the means to gradually manage a multitude of professional writing situations on their own.

The students began with some general exercises to start them thinking about audience, purpose and strategy (Swales \& Feak 1994). They then studied examples of some of the target genres, and discussed the rhetorical and social purposes the genres' structure was related to. Students were then asked to reproduce the genre using a task-based scenario that provided necessary clues about audience and purpose to allow them to more effectively construct their writing strategies. In accordance with the process-oriented aspects of the writing pedagogy, the following week their papers were collected, marked, and returned to them with a penciledin grade. Students were asked to revise and resubmit.

The questionnaires collected at the end of the first course identified three principle criticisms of the approach: (1) there was too much outside work; (2) the course content was too 'esoteric' and not grounded enough in students' specific needs; and especially, (3) students had an adverse reaction to the approach's underlying assumption that learning to write best occurs through an individual's own process of discovery. Instead, students wanted a standard correction after doing each homework assignment (38 from 73 responses). They wanted to be told what the 'right answer' was, as reflected in the following comments:

"Where is the standard correction ('correction type') we asked for?"

"You need to give us the standard correction..."

"A standard correction would be useful to us to help us understand the documents' structure."

"To make this class better: have an example type of the exercises you ask us to do so we know what direction we need to go in." 
"Standard correction desirable."

"We didn't get our standard correction! What a shame!"

"Because everyone doesn't write their report, GS-text or memo in the same way, it would have been interesting to have a standard text type."

"Having a standard correction of the exercises would allow us to evaluate our difficulties as well as our progress, and give a real idea of what we are aiming for."

The demand for a standard correction of the homework assignment was interesting because the students had in fact been given several examples of the genre studied. The target genres' rhetorical structure and language were thoroughly discussed and analyzed in class before students were asked to recreate the genre based on a task-based scenario. And yet, as can be seen in their comments, the students were frustrated with the course because they felt they were having to 'guess' at the answer. In effect, using a discovery process to teach forms of writing was a central element of the pedagogy in the first version of the course; students were expected to gradually learn to reproduce the targeted genres' structure through an instructor-student dialogue. Because no standard correction, or 'correction type' was given to the students after the assignment was completed, they were effectively being asked to discover the answer on their own. Guidance was provided, but only 'from the margins', so to speak. The students were required to work toward a suitable answer on their own, using instructor-guided trial and error.

Another criticism of the process-genre approach was apparent in some students' perception of the course's relevance. A number of students complained that they were beyond needing to think about audience-purpose-strategy because "this [was] stuff that [they] already did in high school". As shown by recent studies on writing instruction in France (Donahue 2000, 2004), writing instruction is in effect heavily emphasized throughout the primary and secondary school curricula. The French school system has a tradition of a "discourseawareness-rich" curricula (Donahue 2004: 68) and writing instruction is integrated into a whole discoursal approach where students are taught to be aware of language and to use it as a tool in their move toward literacy. As a result, perhaps, the students failed to see the relevance of continuing to learn about forms and situations of writing. Now that they were at the university, they wanted to have more advanced knowledge about using English in professional situations. Although some students did recognize that learning how to write different professional genres was useful, the negative language used by the first group, and their negative focus on 'audience-purpose-strategy' pointed to underlying attitudes toward writing that considered it to be an easily transposable and transparent skill. 


\section{Second application of the process-genre approach}

As a result of these first reactions, which showed a rejection of a discovery process for learning as well as negative attitudes toward writing instruction, the language used in the second version of the course, as reflected in the first-day handout, was made much more pragmatic. The abstract 'jargon' of writing pedagogy was eliminated. The first-day handout no longer mentioned knowledge, but skills; it no longer talked about genres, but models; it did not talk about writing but about communication. The explicit language of audience-strategypurpose was also hidden, except as a passing mention made in the introduction to the course; no mention was made of needing to learn how to become autonomous writers, and the approach emphasized how students could 'do' things with words (Austin 1962), as seen below:

What are Languages for Specific Purposes (LSP)? Two views.

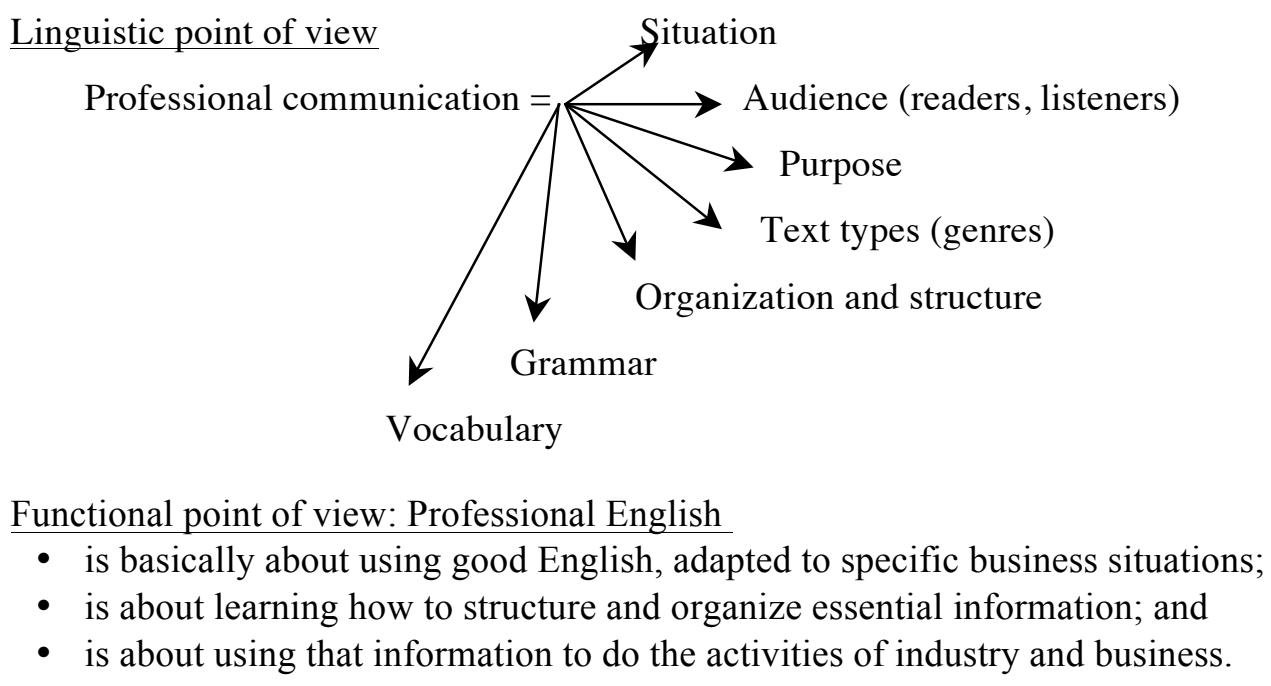

\section{Skills for Professional English}

This semester, you will work on the following skills, which are the basis for all effective, written professional communication:

1. The basics of good English:

- Clear, concise language

- Clear structure and organization

- Good grammar and punctuation

2. Specialized language structures:

- Specific professional genres and their organization

- Formulaic language (grammar, terminology, collocations)

3. Thinking of communication as a strategy for getting things done:

- Applying linguistic skills to particular communicative situations

- Communicating not to yourself, but to your readers

- Planning, writing and revising texts to best respond to readers' expectations 
In addition, the corrections of students' papers were made more concrete in order to provide them with a more standard correction. A course segment based on the consistent patterns of error identified in their papers (both grammatical and rhetorical) was devised. These themes of error were discussed and corrected in class, with students' own errors having been anonymously compiled as exercises to correct together in class. Their response to the exercise was generally positive and they seemed encouraged to be able to identify and correct the typical errors they and their classmates were making.

The error worksheet was a compromise intended to give students a more definitive answer, all the while encouraging them to integrate the answer on their own. In addition, it allowed the class to address issues of genre structure, the characteristics of professional discourse, French native speaker errors in English, as well as the target genre's typical implicit and unstated content (Swales 2004, Huckin 2002, Dressen 2003). For instance, the error worksheet provided many opportunities to address the underlying propositions of the expressions students had learned in other English courses, but without having necessarily learned what situations were or were not appropriate to use them in. In one scenario, for example, students were asked to write to an advertising firm in New York to inquire about underfoot advertisements for their sporting goods store, and to suggest a potential business partnership. It took them quite by surprise to learn that ending their letter, as almost all of them did, with "Thank you for processing this request" was not wholly appropriate.

Despite the interest they showed in these unexpected discoveries, at the end of the second course students were once again globally dissatisfied. First reflected in their comments were the ever-present institutional constraints. In our department, as is typical of many French universities (Taillefer 2007), students attend between 25-35 class contact hours per week and often hold outside jobs to pay for their studies. Process-genre writing needs both time and investment, however. Students can go as far as they wish, but in reality at the end of the day they have little time or energy left for careful reflection and writing.

Also reflected in their comments were their continuing concerns over not receiving enough explicit direction. They still felt lost, as can be seen in the following comments which, while they are more mitigated than the first group's comments, still reveal a similar insecurity at not receiving a standard correction ( 23 from 71 responses). Once again, it is to be noted that the structure and examples of the target genres were provided and discussed before each assignment was given:

"We never really get a standard correction of our homework, even though it would be very helpful to allow us to understand." 
"We only have some points to work with, but not all. We don't have all the tools we need."

"Clues are given only after when they should come before."

"We spend a lot of time preparing, without knowing if it's good or bad."

"Working alone on unknown documents is 'dangerous' because we don't know what we're doing."

"We need more examples, more exercises to practice."

"We need more exercises; even if we have a model, it's very difficult to do it for the first time."

"This class would be better, I think, if you could give more details on what we have to do, the way we have to write a certain paper... As far as I'm concerned, I was kind of lost, wondering what I was supposed to do."

One other comment appeared particularly insightful and relevant to the problem being raised here. This student wrote on her or his questionnaire:

"We know what we don't have to do but not precisely what to do. Maybe it's your method to make us think by ourselves, but we don't know how to do it."

This second set of reactions highlighted the continuing incompatibility of using a typical process-genre approach to teach EAP to these French university students. Although the 'esoteric' language of writing pedagogy and audience-purpose-strategy, criticized by the first group, had been eliminated, although 'skills', 'communicating' and 'doing' were emphasized over 'knowledge' and 'writing', and despite concrete exercises and individual text corrections which showed the students why and how their writing strategies needed to be improved, the students still did not find the course helpful. They had not found the support they needed to feel as though they were learning.

To gain some insight into their reactions, and before examining the third version of the course, in the next section we will consider some of the assumptions about the university writing task these French students may have been bringing with them into the classroom.

\section{Educational profile of the French student writer}

Donahue (2000) has examined and compared high school writing strategies and instruction in the United States and France during the early 1990's. Her findings are relevant here in how they set the basis for understanding student behavior in a French university EAP classroom by describing the ideas about writing students in France come to the university with. As she found, primary and secondary students in France at the time of her study were writing as much, if not more than, their school-aged American counterparts. While this might lead one to believe that French university students should be prime candidates for working in a writing-rich, process-genre approach to EAP/EPP, in fact a number of cultural and institutional differences cause a quite different outcome. 
One first part of the explanation for the difficulty encountered in using a process-genre approach can be found in the purpose for writing instruction in primary and secondary school. All writing instruction is heavily centralized in France; the form it takes is often mandated by the National Ministry of Education with the explicit purpose of preparing students to pass the Baccalauréat, or high school exit exam. What this entails is that over the years, French children are taught to write and master a number of school-based genres that are inscribed within the national education program. And so, while in primary school French students learn to write the summaries, narratives and other stories similarly expected of their American counterparts, during the middle school years, their writing comes to differ fundamentally from the process of 'self-discovery' writing found in US schools. As found by Donahue (2000), by middle school discovery writing is no longer used; the narrative for French students, for instance, becomes a story that has a thesis and which lacks the underlying motive of selfdiscovery or self-understanding commonly promoted in writing instruction in the US. During high school, French students then learn to write the highly structured 'dissertation', topic synthesis and other argumentative texts. Research-style papers, usually informative, are written in nearly every subject, and extensive writing is omnipresent throughout the curriculum (Donahue 2000, 2004). Once students arrive at the university, however, there is no longer any systematic writing instruction.

According to Donahue (2004), this particularity can be explained by the fact that French students learn to master school genres for one immediate and pressing reason, and this reason is not necessarily to become 'better writers' or 'better learners'. Instead, all writing instruction is geared to help students pass the Baccalauréat. In order to pass the exit exam, students must have acquired "good" writing strategies and demonstrate that they have learned the following skills, as mandated by the French Ministry of Education (cited by Donahue 1996):

- to think abstractly;

- to argue effectively in an elegant and precise prose;

- to possess a rich personal culture, developed from a list of readings established by the Education Ministry;

- to produce a heavily normed text on demand;

- to write for a 'general audience', e.g., the universal and educated reader.

This list summarizes the writing skills students are expected to develop before coming to the university.

A second reason that may explain the EAP students' reaction is that the school genres and writing skills they have learned during secondary school are expected to carry over into 
all other types of writing required in their academic, professional or private lives. However, the French education system's early specialization in writing also specifically prepares students for one particular type of university, theory-based writing: exam writing. Given the massification of French higher education since the 1970's (Burgel 2006), end-of-the-semester exams have become the primary means for evaluation at the university, and individual research and topic papers are rare (Donahue 2004). As a result, today's university students not only lack experience in other types of writing, including disciplinary and/or workplace genres, but also may fail to see the importance of continuing to spend more time learning how to write.

Donahue (2000) makes one further crucial observation that may shed further light on the reaction of the EAP course's students. She observed that children in French primary and secondary schools were not taught to write by using writing to learn and by revising writing based on teacher or peer feedback. Rather, "process writing" was considered a process of repeating similar forms. As Donahue (2000) argues, writing was learned in the French school system by having students write the same kinds of essays repeatedly.

Moreover, Donahue (2000) observes that the French high school students in her study tended to struggle with the idea that it was acceptable to modify, rethink and change what they had written, simply because they had not been taught to write in that way. Rather, students had been traditionally taught to do all the thinking in their heads and plan before they actually sit down to write. This is an important skill to acquire for later success at the university. Indeed, as French research into student writing has shown (Piolat \& Roussey 1996), the better students plan their outline, the better the quality of the text produced during the examination.

One generalization that can be tentatively made at this point is that writing in French schools has typically been considered to be the final, end part of the process - not the beginning of a dialogue nor even part of the learning process. ${ }^{i}$ As a result, one conjecture is that the French university students observed during the case study may have come to the EAP course with no real underlying need for, or experience in, process learning and dialogue about genres. In light of Donahue's contrastive work on French and American high school writers, one can better contexualize the negative reactions the French university students were having toward the EAP course's process-oriented and genre-based pedagogies, which had been constructed out of cultural resources that were unfamiliar to the students:

- because French students spend a good deal of time learning to write at primary and secondary school, the students in the course considered that writing was an 
occupation for school children and not one worthy of pursuit at an institution of higher education;

- because they had spent so much time learning to write in secondary school, with some of them having become quite good at it, they generally saw themselves as good writers. However, as is often the case, writing was also considered to be a transparent and generalizable skill that required no more special effort once it had been learned. Holding such attitudes unknowingly put them at a disadvantage, given the difficulties inherent in applying school writing to other types of writing (Beaufort 1998);

- process writing at the time these students went through the French school system implied that they had learned to write by repeatedly adapting their writing across different writing assignments to conform to a model. They did this by relying on the standard correction of a writing assignment. The grade received on a particular writing assignment, and the differences perceived between their own writing and the teacher's standardized answer, was their primary guide to improving their writing strategies;

- writing was not viewed as an indication that learning was taking place. To the contrary, writing was the ends, not the means, to their learning;

- student-instructor dialogue about writing had generally been absent from their school experience; the students had not been asked to revise and resubmit their papers once they had been turned in and graded the first time;

- the students in the EAP course did not realize that the texts they turned in for the course were unfinished products, during which time meaning was still being constructed;

- given their attitudes toward writing, the students generally did not consider writing to be a valuable means for exploring their engagement with the socio-political realities and potential target situations of their lives. Indeed, students reacted quite strongly against exploring their personal engagement in the classroom. ${ }^{\text {ii }}$

In many ways, university study in France today is still modeled on the 'grandes écoles' educational system (Burgel 2006, Veltz 2007), intended to transmit a set of skills to students rather than provide them with "innovating, character-building experiences," potentially transforming them into the "independent and creative learners" valued in other educational systems (see Kruse 2006 for a view on learner roles in German universities or Russell 2002 for American universities). An earlier study (Madero 1986) of pedagogical practices in French universities concluded, for example, that despite a growing interest in university-level pedagogy, the overwhelming perception of the student-teacher interaction in France was still to transmit skills in an institutional setting rather than to dialogically establish the type of relationship recognized in the research literature as being essential to the learning process. As a result, the students in the EAP course were likely unsure of how to react in the course, given their own expectations about the teacher-student-knowledge triad. While the instructor 
considered their expectations of the interaction to be limited, they nonetheless clearly oriented the students' assumptions about how they should be learning.

\section{The process-genre approach revisited: Final discussion and implications}

In light of these and other observations, it was concluded that the process-genre approach used in the EAP course was interfering with the students' learning patterns. In part, this interference was explainable by the apparent differences in deductive versus inductive reasoning that distinguishes discourse and teaching styles in French and English (Bachschmidt 1997). Such a distinction would, for example, involve discussing examples of the target genre prior to writing (deductive), rather than having students work through the problem first and then compare their solution with a standard correction, thereby allowing them to uncover the solution on their own at a later stage of the learning process (inductive).

A large part of the interference could thus be traced to the underlying assumptions that shaped learning expectations on each side, and especially, at what point the consolidation of learning ('U-curve') was expected to take place. On one side were the French students, whose educational experiences had taught them that writing was not the means, but the ends, to their learning. They had also learned to rely on the instructor, not for guidance in discovering the answer, but to give them the answer to model. On the other was the writing instructor, educated and trained in North American universities, who expected students to learn by writing and to find meaning in the process of learning how to write. The interference was thus caused by differences in the unspoken assumptions each side held about what was the most efficient way to learn.

In addition, the French students in the EAP courses did not expect to come for a course in process and discovery learning. When faced with the new learning methods, they either lacked the confidence to 'grapple' with the problem - process learning had been absent from their educational curriculum since primary school - or they were frustrated because they did not have enough input to confidently reproduce the models on their own. They wanted the answer to assimilate so that they could become 'autonomous'; without the instructor's final word, they felt they were missing something in their learning cycle and would be unable to find the answer on their own. Paradoxically, the students did not realize that they did have models to work from and that they had actually learned something in the course: despite their hesitations, they had turned in quite good texts after revision and had received relatively good grades. However, they had missed the point of their learning and had 
not realized that they had actually integrated structures they could use and later apply on their own.

As a result, the mid-point assessment of the process-genre approach with these groups of French student writers was somewhat conflicting. On one hand, the teaching strategy seemed successful because the students were demonstrating learning in their writing assignments. But at the same time, it was a failure because the students themselves had little confidence in this type of learning and were not convinced of the outcome. It was also a failure because the students did not see how the approach was supporting their growth toward autonomy.

In response to the students' institutional expectations and prior writing experiences, two final adjustments to the teaching approach were made. First, a three-part approach called "Directed Communicative Modeling" (Dressen 2004) was formalized. It combined the teaching of formalized structures, authentic communicative situations and successive modelization, each of which was emphasized at various points throughout the semester, depending on where the students were at in their learning cycle:

Direct teaching of linguistic structures. A genre-based approach gives students the concrete, formal tools and models (e.g., lexical, grammatical and discoursal) of the typified genres used by professionals.

Communicative process. A process-oriented approach provides students with multiple opportunities to strategically practice adapting the tools and skills they have learned by writing in response to task-based scenarios.

Dialogical modeling. Finally, through a process of ongoing student-teacher dialogue, the normed structures are increasingly approximated.

On the surface, this approach appears quite similar to a typical process-genre approach. However, it provides a situated response both to the concerns students had expressed about lacking instructional guidance, as well as to the specific context of having learned to write in the French school system, where 'process' entails learning to write by repeatedly producing similar forms based on a model. In practice, this entailed providing more in-class exercises and hands-on experience before the students were actually asked to write the assignment. They were thus able to go through the process of learning the genre's form and compare their learning with a standard correction before having to actually reproduce the genre in response to a task-based, open-ended scenario. Graded revisions then allowed students to better grasp the genre's pragmatic, rhetorical and situational difficulties. 
One other minor, but important, adjustment was also essential to changing students' attitudes toward the approach. As observed by Donahue (2000), French student writers lack the experience of revision. Therefore, in addition to the error-sheet exercise, students also received a personal 'letter' which stated what was done well and highlighted specific areas of difficulty. In a few words, it explained what they need to do to revise their text, but still without necessarily doing it for them.

In response, students were for the first time able to explicitly identify the instructorstudent dialogue as an interaction that was giving them answers. In the previous versions of the course, students had also received lengthy and well-intended comments. However, these comments had been written directly on their papers, like an editor writing in the margins. Yet, because French students do not expect to learn to write using student-teacher dialogue, they had been unable to identify what the purpose of the comments was and how to work with the dialogue and error support provided in the corrections. In other words, because the French students were unfamiliar with the 'revision genre' instructors use in the process-genre approach to help students improve their writing, they did not realize that the text they had turned in was really only the mid-way point in their learning.

This time, however, the rhetorical intention of a specific teacher-genre ('written comments') was made explicit to them because it was reformulated as a dialogical genre they could easily identify: a letter. They were no longer receiving 'scribbles' they did not know what to do with, but were individually addressed and given point-by-point feedback. As a consequence of receiving individual feedback they could identify, they were able to confidently close the cycle of their learning. In turn, they better accepted the messiness of the process of looking for the answer themselves, because they knew the instructor would provide the answers and support they needed in a format they could understand.

At the end of this third course, the questionnaires indicated quite a different response to the approach. While one student was honest, writing on her or his evaluation sheet, "I didn't always understand what [your comments] meant", a clear majority (42 from 63 students, or 67\%) explicitly stated that they were receiving the guidance they needed to understand and correct their errors. Students for the first time overwhelmingly commented that the EAP course was useful.

\section{Conclusion}

To conclude, the process-genre approach to teaching EAP appears useful to teaching writing cross-culturally in the European university system because the approach undeniably 
reflects the underlying cognitive processes of how people learn (e.g., discovery of patterns and variation, dialogue, application, verification, dialogue, realignment). At the same time, however, it is undeniable that despite one's best intentions, neither the process-oriented nor the genre-based aspects of the approach are devoid of underlying cultural baggage. As a result, using the approach in different cultural contexts challenges our often unacknowledged knowledge schemas and deep-seated philosophies about learning that we assume are inherently shared by those we teach. As has been seen here, from culture to culture, learning styles can be quite different, ways of knowing can be different, and institutional purposes can be different. Much of what caused the mismatch between the process-genre approach and the French students I was working came from deep-seated cultural assumptions and institutional expectations. This is, of course, a point one can usefully be reminded of from time to time, despite the numerous references to it in the literature (Cope \& Kalantzis 1993, Ramanathan \& Atkinson 1999, Hyland 2003), to name but a few. Furthermore, the process-genre approach cannot be truly universal simply because the genres taught in a writing course are always intimately tied to the local conditions of their use; understanding those conditions includes accounting for the complex web of social structures, institutions and interactions that characterize particular communities of practice and their activities (Räisänen 2002).

Of course, the process-genre approach is highly malleable and can be reoriented to reflect different learning styles, ways of knowing and institutional imperatives. To do so, however, the instructor's local knowledge is essential, not only for understanding how students are used to learning and what role they are expected to play in their institutions, but also for gauging exactly how to balance the teaching of structure (genres) and process (dialogue and discovery) in order to best facilitate the students' culturally unique learning process.

In this sense, a fine-tuned process-genre approach to teaching EAP might indeed allow for greater harmonization in English teaching across European universities. This can be achieved in terms of general program content and course outcome expectations. It can also increase a shared understanding of the potential for EAP learning among students from different European countries, thereby facilitating exchanges between universities and creating a shared culture of learning and doing. Facilitating cultural exchanges, within Socrates or Erasmus programs, is of course one of the primary objectives that lie behind the Bologna process and its LMD system. Whether the Bologna process will be the impetus behind a shift in cultural attitudes toward learning, or merely the manifestation of changes already underway, is of course a valid question. It has been my personal observation that the latter 
may tend to be closer to the truth. Certainly, without exception, the Italian and Spanish undergraduate students who have attended my EAP courses over the past few years have come well-equipped to work within the same learning environment that has shown itself to be problematic for their French counterparts. This suggests to me that a shift in attitudes towards learning, and towards writing, may already be in progress in these other Latin-based, southern European countries which, at the same time, give many indications of having institutional structures and functioning similar to that in France.

However, while a harmonization of teaching approaches and of learning outcomes may be possible, and perhaps in some sense even desirable, it is important to recognize that harmonization can only be accomplished at the expense of losing other divergences which are equally as important for defining national identities. Clearly, the institutional history behind writing pedagogy in France and the expectations that go along with it play a large role in defining the attitudes toward writing and learning students come to university with. At the same time, these are expectations that have been carefully tailored to fit the specific needs of French society and the perennialization of its institutions. Using and adapting a process-genre approach to writing instruction inherently implies wanting to change learning behaviors, however much one argues for its benefits. Even if the process-genre approach is adaptable to local contexts and may seem genuinely beneficial in helping students to become autonomous writers, its unavoidable cultural bases necessarily pushes students to adapt because they are being introduced to new ways of learning and thinking about themselves that differ from the institutional environment in which they grew up. This, in turn, implies the co-construction of new expectations and social identities.

Creating new expectations and social identities, by aligning old ones with practices in other cultures, may, however, risk undermining the uniqueness of a particular voice that proposes an alternate way of seeing the world. While a harmonization among views towards learning may be possible, it is also necessary to reflect on exactly what it is we hope to achieve by decreasing the divergences that underscore the richness of the European fabric.

\section{Notes}

1 There is evidence, however, that writing pedagogy at the primary and secondary school levels is changing, with more emphasis being placed on teacher-guided process writing, as seen in the types of training future teachers now receive in national teaching institutes (Plane 2003; Donahue 2004).

2 A British colleague, who has taught in my department for nearly 30 years, read and commented on an earlier version of this paper with the following insight on the French 
university's mission and its influence upon attitudes toward learning: "The French University is a public institution where students go to acquire skills they can use in their working life. The educational system is designed to provide skills and a common frame of reference to promote social cohesion, and so is very conservative and institutional... The teachers, who are public servants, deliver the goods in a standard format; the teacher has little or no 'pastoral' role. The boundary between the public and private spheres in France accounts for a lot: education is in the public sphere, personal development belongs to the private sphere. Although teachers can and do help students to develop personally, this happens outside the system. Personal qualities such as initiative, conviction, inventiveness, are not normally evaluated by the educational system, or only marginally..." (R. Ryan, p.c.)

\section{References}

Austin, J. 1963. How to do things with words. Oxford: Oxford University Press.

Bachschmidt, P. 1997. The construction of argumentation in engineering research articles: discoursal differences between French and English speakers. ASp: la revue du GERAS 23/26: 197-207 [in French].

Bhatia, V. 1993. Analysing genre: Language use in professional settings. London: Longman.

Bhatia, V. 1999. Integrating products, processes and participants in professional writing. In Writing: texts, processes and practices, C. N. Candlin \& K. Hyland (eds.), 21-39. London: Longman.

Bizzell, P. 1992. Academic discourse and critical consciousness. Pittsburgh: University of Pittsburgh Press.

Bjork, L, Braeuer G., Rienecker, L., Stray Jörgensen, P. (eds). 2003. Teaching academic writing in European higher education. London: Kluwer Academic Publishers.

Burgel, G. 2006. The university, a French dilemma. Paris: Hachette [in French].

Cope, B., Kalantzis, M. (eds.). 1993. The powers of literacy: a genre approach to teaching writing. Bristol, PA: Falmer Press.

Donahue, C. 1996. French students' writing ability as a method of transcending the boundary into post-secondary studies. Paper presented at the Conference on College Composition and Communication, Milwaukee, Wisconsin, 1996.

Donahue, C. 2000. Genres, textual movement and subjectivity in learning academic writing: Interpreting the discourse of French and American student writers. Unpublished $\mathrm{PhD}$ Dissertation, University of Paris 5 [in French].

Donahue, C. 2004. Writing and teaching the disciplines in France: current conversations and connections. Arts and Humanities in Higher Education 3: 59-79.

Dressen, D. 2003. Geologists' implicit persuasive strategies and the construction of evaluative evidence. Journal of English for Academic Purposes 2: 273-290.

Dressen, D. 2004. Directed communicative modeling: contributions of the genre approach to teaching professional English. Les Cahiers de l'APLIUT 23: 89-103 [in French].

Ferris, D. 1997. The influence of teacher commentary on student revision. TESOL Quarterly 31: 315-339.

Freedman, A., Medway, P. 1994. Genre in the new rhetoric. Bristol, PA: Taylor \& Francis.

Goldstein, L. 2004. Questions and answers about teacher written commentary and student revision: teachers and students working together. Journal of Second Language Writing 13: $63-80$. 
Halliday, M.A.K. 1994. An introduction to functional grammar (2nd ed.). London: Edward Arnold.

Huckin, T. 2002. Textual silences and the discourse of homelessness. Discourse and Society 13: 347-372.

Hyland, K. 2003. Genre-based pedagogies: a social response to process. Journal of Second Language Writing 12: 17-29.

Hyland, K. 2004. Genre and second language writing. Ann Arbor: The University of Michigan Press.

Hyland, K., Hyland, C. (eds.). 2006. Feedback in second language writing. Cambridge: Cambridge University Press.

Johns, A. 1997. Text, role and context: developing academic literacies. New York: Cambridge University Press.

Kruse, O. 2006. The origins of writing in the disciplines: traditions of seminar writing and the Humboldtian ideal of the research university. Written Communication 23:331-352.

Madero, M.C. 1986. Contributions to an analysis of pedagogical methods at the university. Unpublished Ph.D. dissertation, University of Bordeaux 2 [in French].

Paulus, T. 1999. The effects of peer and teacher feedback on student writing. Journal of Second Language Writing 8: 265-289.

Piolat, A., Roussey, J-Y. 1996. Students' drafting strategies and text quality. Learning and Instruction 6: 111-129.

Plane, S. 2003. Learning to write in primary school. Repères: 26-27 [in French].

Räisänen, C. 2002. The conference forum: a system of interrelated genres and discursive practices. In The language of conferencing, E. Ventola, C. Shalom, S. Thompson (eds.), 69-94. Frankfurt: Peter Lang.

Ramanathan, V., Atkinson, D. 1999. Individualism, academic writing, and ESL writers. Journal of Second Language Writing 8: 45-75.

Reinecker, L., Stray Jörgensen, P. 2003. The (im)possibilities in teaching university writing in the Anglo-American tradition when dealing with continental student writers. In Teaching academic writing in European Higher Education, L. Bjork, G. Braeuer, L. Rienecker, P. Stray Jörgensen (eds.), 101-112. London: Kluwer Academic Publishers.

Russell, D. 2002. Writing in the academic disciplines: a curricular history (2nd ed.). Edwardsville: Southern Illinois University Press.

Swales, J.M. 1990. Genre analysis: English in academic and research settings. Cambridge: Cambridge University Press.

Swales, J.M. 2004. Research genres: explorations and applications. Cambridge: Cambridge University Press.

Swales, J.M., Feak, C. 1994. Academic writing for graduate students: a course for nonnative speakers of English. Ann Arbor: The University of Michigan Press.

Taillefer, G. 2007. The professional language needs of Economics graduates: assessment and perspectives in the French context. English for Specific Purposes 26: 135-155.

Tuzi, F. 2004. The impact of e-feedback on the revisions of L2 writers in an academic writing course. Computers and Composition 21: 217-235.

Veltz, P. 2007. Must we save the 'grandes écoles'? From a culture of selection to a culture of innovation. Paris : Presses de Sciences Po [in French].

Zamel, V. 1983. The composing processes of advanced ESL students: six case studies. TESOL Quarterly 17: 165-187. 